\title{
Effect of leukocyte inhibitory factor on neuron differentiation from human induced pluripotent stem cell-derived neural precursor cells
}

 \\ XIAOSONG HE ${ }^{1-3}$, QINGQING LI ${ }^{1-3}$, YINSHAN BAI ${ }^{1}$, SHANSHAN LIU ${ }^{1}$ and DAHONG LONG ${ }^{1-3}$ \\ ${ }^{1}$ Key Laboratory of Neuroscience, School of Basic Medical Sciences, ${ }^{2}$ Institute of Neuroscience and \\ The Second Affiliated Hospital, ${ }^{3}$ Key Laboratory of Neurogenetics and Channelopathies of Guangdong Province and \\ The Ministry of Education of China, Guangzhou Medical University, Guangzhou, Guangdong 511436, P.R. China
}

Received December 2, 2016; Accepted January 5, 2018

DOI: $10.3892 /$ ijmm.2018.3418

\begin{abstract}
Direct derivation of human induced pluripotent stem cells into neural precursor cells and differentiation of these into neurons holds great promise in the cell therapy of neurodegenerative diseases. However, the availability and survival rate of neurons requires improvement. In the present study, it was found that the addition of $5 \mathrm{ng} / \mathrm{ml}$ leukocyte inhibitory factor (LIF) during the process of differentiation significantly improved the expression of neuron-specific class III $\beta$-tubulin (TUJ1) and microtubule-associated protein 2 (MAP2), as detected by immunofluorescence and western blotting. In addition, LIF improved the cell viability, increased the expression of phosphorylated-protein kinase B (AKT), downregulated the expression of proinflammatory cytokines, including interleukin-1 $\alpha$ (IL- $1 \alpha)$ and tumor necrosis factor- $\alpha$ (TNF- $\alpha$ ), and upregulated the expression of anti-inflammatory cytokines, including interleukin-10 (IL-10) and transforming growth factor- $\beta$ (TGF- $\beta$ ). After adding the phosphatidylinositol 3-kinase (PI3K)/AKT signaling inhibitor LY294002 or wortmannin to the LIF differentiation group, LIF-induced changes in the protein expression of TUJ1 and MAP2 were reversed, but this effect could not be prevented by rapamycin, a mechanistic target of rapamycin signaling inhibitor. The expression of cytokines associated with inflammation and cell viability was reversed by LY294002 and wortmannin, but not by rapamycin. In conclusion, LIF could improve neuronal differentiation and survival through the activation of PI3K/AKT signaling and the
\end{abstract}

Correspondence to: Professor Dahong Long, Key Laboratory of Neuroscience, School of Basic Medical Sciences, Guangzhou Medical University, 195 Dongfeng Xi Road, Guangzhou, Guangdong 511436, P.R. China

E-mail: longdahong88@qq.com

*Contributed equally

Key words: human induced pluripotent stem cells, leukocyte inhibitory factor, inflammation, phosphatidylinositol 3-kinase/protein kinase B signal, neural precursor cells anti-inflammatory effect. The anti-inflammatory effect may be mediated by the activation of PI3K/AKT.

\section{Introduction}

Human induced pluripotent stem cells (hiPSCs) have broad prospects for application in the field of regenerative medicine due to their three germ layer differentiation ability and patient-specific cell source $(1,2)$. Therefore, through differentiation into neural cells, hiPSCs can provide a good cell source for the cell therapy of neurodegenerative disease (3). It is known that, during the induction period, there is a precise molecular regulation mechanism, developmental sequence, overlap of time and overlap of space that should be followed $(4,5)$. In the present study, the differentiation of mesodermal and endodermal cells was reduced through inhibition of bone morphogenetic protein (BMP) and transforming growth factor- $\beta$ (TGF- $\beta$ ) signaling using the signaling pathway inhibitors LDN193189 and SB431542. In this manner, a large number of outer germ layer cells were obtained from which neural progenitors were derived. Efficient neuron differentiation from derived neural precursor cells (NPCs) in the cell treatment of neurodegenerative diseases is critical, but the low differentiation rate and poor survival state are still to be improved in vitro or in vivo $(6,7)$. In previous studies, the addition of antioxidant and anti-inflammatory cytokines to the differentiation medium, and the combined use of neurotrophic factors during the differentiation period were able to improve the differentiation ratio and the survival state $(8,9)$. However, the mechanism has not yet been clarified.

Leukocyte inhibitory factor (LIF) is a highly conserved gene of the interleukin (IL)-6 family (10). LIF has multiple functions, including the maintenance of the undifferentiated state of mouse embryonic stem cells (mESCs), the proliferation of primordial germ cells, and functions as a mediator in implantation and decidualization (11). It has been found that Janus kinase/signal transducer and activator of transcription (JAK/STAT3), protein kinase B (AKT), extracellular signal-regulated protein kinases $1 / 2$ (ERK1/2) and mechanistic target of rapamycin (mTOR) signaling pathways are involved in the biological function of LIF (12-15). LIF could improve cell proliferation in fibroblasts 
and cardiomyocytes through activating the PI3K-sensitive AKT kinase $(16,17)$. Phosphatidylinositol 3-kinase (PI3K)/AKT signaling is involved in numerous events in neuronal proliferation and differentiation. Downregulating PI3K/AKT signaling could inhibit neuroendocrine differentiation. By contrast, upregulating of this signal could increase the neuronal differentiation from mouse cochlear neural stem cells $(18,19)$. It has been reported that LIF has a similar function to neurotrophic factor in neuronal differentiation from the mouse neural crest. Moreover, LIF can improve the maturation of sensory neurons and maintain their morphological characteristics (20). In a study using mice with spinal cord injury, LIF-treated mice manifested greater recovery of locomotor behavior due to an increase in the number of neurons and NPCs in the brain (21). However, the mechanism of LIF in neuron development has not been elaborated.

Anti-inflammation is one of the strategies for the treatment of neurodegenerative diseases and for neuronal protection $(22,23)$. Certain studies have demonstrated that methylprednisolone facilitates the survival of new neurons and improves the neurological deficit following transient cerebral ischemia through the suppression of inflammatory reactions (24). Anti-inflammatory treatment could protect the dopaminergic neurons in 6-hydroxydopamine-lesioned rats through targeting not only the microglia, but also the other immune cells, including cluster of differentiation 163-positive macrophages (25). Inflammation of the neurons causes the release of inflammatory cytokines, including IL-6, IL-5 and LIF (26). In addition, LIF serves an important role in the inflammatory responses. It has been reported that injecting lipopolysaccharide (LPS) into the trachea of rats could induce the expression and secretion of LIF in bronchoalveolar cells (27). Moreover, inflammatory cytokines, including IL-6 and tumor necrosis factor- $\alpha$ (TNF- $\alpha$ ), could increase the mRNA or protein expression of LIF during cell culture $(28,29)$. However, studies on the stimulation of an anti-inflammatory effect by LIF in in vitro neuronal differentiation are rare.

In the present study, we would use LIF to activate the PI3K/ AKT signal and induce the anti-inflammatory effect during the neuron differentiation from hiPSCs derived NPCs. This effect might improve the neuron differentiation ratio and survival state.

\section{Materials and methods}

Culture of undifferentiated hiPSCs. The hiPSC cell line and the H9 embryonic stem cell line (gifts from Professor Lan Feng, Beijing Anzhen Hospital Beijing Institute of Heart Lung and Blood Vessel Disease, Capital Medical University, Beijing, China) were maintained in essential 8 medium (Table I) (Thermo Fisher Scientific, Inc., Waltham, MA, USA) in Matrigel (B\&D Technologies, Macon, GA, USA) pre-coated dishes, $37^{\circ} \mathrm{C}, 5 \% \mathrm{CO}_{2}$. The hiPSCs were passaged every 4-7 days when the cells reached $80-90 \%$ confluence.

Neural induction. For neural induction, the hiPSCs were split using accutase (Thermo Fisher Scientific, Inc.) for $5 \mathrm{~min}$ and seeded in a Matrigel pre-coated 6-well plate at a density of $1.6-2 \times 10^{4} \mathrm{cells} / \mathrm{cm}^{2}$ in the presence of $5 \mu \mathrm{M}$ Q-associated, coiled-coil-containing protein kinase (ROCK) inhibitor (Selleck Chemicals, Houston, TX, USA). Following 1 day of incubation, medium containing ROCK inhibitor was aspirated,
Table I. Culture media and reagents.

\begin{tabular}{|c|c|}
\hline Medium & Reagents \\
\hline hiPSC & E8 and its supplements \\
\hline NPC & $\mathrm{DMEM} / \mathrm{F} 12^{\mathrm{a}}$ \\
\hline \multirow[t]{5}{*}{ induction } & Neurobasal medium $^{a}$ \\
\hline & $1 \% \mathrm{~N} 2^{\mathrm{a}}$ \\
\hline & $2 \% \mathrm{~B} 27^{\mathrm{a}}$ \\
\hline & $10 \mu \mathrm{M} \mathrm{SB} 431542^{\mathrm{b}}$ \\
\hline & $100 \mathrm{nM}$ LDN193189 \\
\hline Neuron & $\mathrm{DMEM} / \mathrm{F} 12^{\mathrm{a}}$ \\
\hline \multirow[t]{8}{*}{ differentiation } & $2 \% \mathrm{~B} 27^{\mathrm{a}}$ \\
\hline & $1 \% \mathrm{~N} 2^{\mathrm{a}}$ \\
\hline & $20 \mathrm{ng} / \mathrm{ml} \mathrm{BDNF}^{\mathrm{c}}$ \\
\hline & $20 \mathrm{ng} / \mathrm{ml} \mathrm{GDNF}^{\mathrm{c}}$ \\
\hline & $0.2 \mathrm{mM} \mathrm{AA}^{\mathrm{b}}$ \\
\hline & $0.5 \mathrm{mM}$ dibutyryl $\mathrm{cAMP}$ \\
\hline & $5 \mathrm{ng} / \mathrm{ml}$ of $\mathrm{LIF}^{\mathrm{c}}$ \\
\hline & LY294002 $(20 \mu \mathrm{M})^{\mathrm{b}}$ \\
\hline
\end{tabular}

${ }^{\mathrm{a}}$ Gibco; Thermo Fisher Scientific, Inc.; ${ }^{\mathrm{b}}$ Merck KGaA; ${ }^{\mathrm{c}}$ Peprotech, Inc. hiPSC, human induced pluripotent stem cells; NPC, neural precursor cell; BDNF, brain-derived neurotrophic factor; GDNF, glial cell line-derived neurotrophic factor; AA, ascorbic acid; LIF, leukocyte inhibitory factor; cAMP, cyclic adenosine monophosphate.

and N2/B27 basic medium (Table I) containing a mixture of 1:1 Dulbecco's modified Eagle's medium (DMEM)/F12 and neurobasal medium, supplemented with 1\% N2 and 2\% B27 (all Gibco; Thermo Fisher Scientific, Inc.) was added. SB431542 $(10 \mu \mathrm{M})$ and $100 \mathrm{nM}$ LDN193189 (both Sigma-Aldrich; Merck KGaA, Darmstadt, Germany) were added to the basal medium to trigger the neural induction. The neural induction lasted 11 days. On day 5 of the induction, the SB431542 was removed. During the induction period, the culture medium was changed every day.

Neural differentiation. On day 11 of induction, the induction medium was changed to differentiation medium (Table I) consisting of DMEM/F12, supplemented with $2 \% \mathrm{~B} 27,1 \% \mathrm{~N} 2$, $20 \mathrm{ng} / \mathrm{ml}$ brain-derived neurotrophic factor (Peprotech, Rocky Hill, NJ, USA), $0.2 \mathrm{mM}$ ascorbic acid (Sigma-Aldrich; Merck KGaA), 20 ng/ml glial cell line-derived neurotrophic factor(Peprotech) and 0.5 mMdibutyryl AMP(Sigma-Aldrich; Merck KGaA). To prepare the LIF-positive differentiation group, $5 \mathrm{ng} / \mathrm{ml}$ LIF (Peprotech) was added to the differentiation medium. To prepare the PI3K/AKT inhibition differentiation group, $20 \mu \mathrm{M}$ PI3K/AKT inhibitor LY294002, or $50 \mathrm{nM}$ wortmannin (both Sigma-Aldrich; Merck KGaA) combined with $5 \mathrm{ng} / \mathrm{ml}$ LIF was added to the differentiation medium. To prepare the mTOR inhibition differentiation group, $100 \mathrm{nM}$ rapamycin (Sigma-Aldrich; Merck KGaA) combined with $5 \mathrm{ng} / \mathrm{ml}$ of LIF was added to the differentiation medium. Derived NPCs were differentiated for 9 days. On culture day 20 (counting the first culture day as the day of the initial derived NPC induction from hiPSCs), the cells were harvested and prepared for further experimentation. 
Table II. Primers used in this study for reverse transcription-quantitative polymerase chain reaction.

\begin{tabular}{|c|c|c|}
\hline Name & Sense primers & Antisense primers \\
\hline$G A P D H$ & CCCATGTTCGTCATGGGTGT & GATGGCATGGACTGTGGTCA \\
\hline OCT4 & TGAGGCCCTGGAGAAAGAGT & TTGCTGGCCTGTCTTCTCTG \\
\hline NANOG & GCAGGGATGCCTGGTGAAC & GGACTGTTCCAGGCCTGATT \\
\hline SOX2 & GGATAAGTACACGCTGCCC & ATGTGCGCGTAACTGTCCAT \\
\hline LIN28 & GGAAAGAGCATGCAGAAGCG & TGATGCTCTGGCAGAAGTGG \\
\hline PAX6 & TGAGGCCCTGGAGAAAGAGT & TTGCTGGCCTGTCTTCTCTG \\
\hline NES & AGTGATGCCCCTTCACCTTG & GCTCGCTCTCTACTTTCCCC \\
\hline$I L-10$ & CGAGATGCCTTCAGCAGAGT & CGCCTTGATGTCTGGGTCTT \\
\hline$T G F-\beta$ & TTGACTTCCGCAAGGACCTC & CTCCAAATGTAGGGGCAGGG \\
\hline$I L-1 \alpha$ & CCTGAGCTCGCCAGTGAAAT & GGTGGTCGGAGATTCGTAGC \\
\hline$T N F-\alpha$ & ТССТСТСТGCСATCAAGAGC & AGTAGACCTGCCCAGACTCG \\
\hline$M A P 2$ & TCTGCACACTCACATCCACC & CTGAGGTCAGCTCTCCGTTG \\
\hline$T U J 1$ & GCTGGTGGAAAACACGGATG & GCCGATACCAGGTGGTTGAG \\
\hline
\end{tabular}

$I L-10$, interleukin-10; TGF- $\beta$, transforming growth factor- $\beta ; T N F-\alpha$, tumor necrosis factor- $\alpha$; MAP2, microtubule-associated protein $2 ; T U J 1$, neuron-specific class III $\beta$-tubulin; NES, nestin; PAX6, paired box 6; LIN28, lin-28 homolog A; SOX2, SRY-box 2; NANOG, Nanog homeobox; OCT4, POU class 5 homeobox 1; GAPDH, glyceraldehyde-3-phosphate dehydrogenase.

Immunofluorescence. The immunofluorescence method was performed as previously described (30), with minor modifications. Briefly, the cells were washed with phosphate-buffered saline (PBS), fixed at room temperature for 20 min with $4 \%$ paraformaldehyde, washed again in PBS 3 times, for 5 min each time, and then permeabilized with $0.3 \%$ Triton X-100/PBS for 10 min. Next, the cells were blocked with $5 \%$ bovine serum albumin (BSA)/PBS for $40 \mathrm{~min}$. The cells were then exposed to primary antibodies diluted in PBS plus $1 \%$ BSA at $4^{\circ} \mathrm{C}$ overnight, followed by incubation with corresponding secondary antibodies at room temperature for $2 \mathrm{~h}$. Cell nuclei were counterstained with 4',6-diamidino-2-phenylindole for $15 \mathrm{~min}$. Samples were analyzed using an inverted fluorescence microscope (IX71; Olympus, Tokyo, Japan) or a confocal Leica TCS SP8 (Leica Microsystems, Inc., Buffalo Grove, IL, USA). All images were acquired under identical settings using IPP7.0 Image Browser software (Olympus) or LAS AF Lite (Leica Microsystems, Inc.). The relative fluorescence intensity was qualified using ImageJ software. Primary antibodies used in this study were: POU domain class 5 transcription factor 1 (OCT4; sc-5279; 1:100 dilution; Santa Cruz Biotechnology, Inc., Dallas, TX, USA), Nestin (A0484; 1:50 dilution; ABclonal Biotechnology Co., Ltd., Cambridge, MA, USA), paired box protein Pax-6 (PAX6; ab5790; 1:750 dilution; Abcam, Woburn, MA, USA), microtubule-associated protein 2 (MAP2; 4542; 1:200 dilution; Cell Signaling Technology, Inc., Danvers, MA, USA), neuron-specific class III $\beta$-tubulin (TUJ1; T2200; 1:200 dilution; Sigma-Aldrich; Merck KGaA), AKT (9272; 1:200 dilution) and phosphorylated (p)-AKT (4060; 1:200 dilution) (both Cell Signaling Technology, Inc.). Secondary antibodies used in this study were fluorescein isothiocyanate-conjugated goat anti-rabbit and Cy3-conjugated goat anti-rabbit antibodies (F-2765 and T-2767; 1:200 dilution; both Thermo Fisher Scientific, Inc.)

Reverse transcription-quantitative polymerase chain reaction (RT-qPCR). Total RNA (hiPSCs, H9, hiPSCs-derived NPCs and neurons differentiated from hiPSCs-derived NPCs) used in the present study was isolated using TRIzol reagent (Takara Bio, Inc., Otsu, Japan). Isolated RNA (1 $\mu \mathrm{g})$ was converted into cDNA using the SuperScript III First-Strand cDNA Synthesis kit (Takara Bio, Inc.). The RT-qPCR was performed as previously described (31) on an Applied Biosystems 7500/7500 Fast Real-Time PCR system (Thermo Fisher Scientific, Inc.) using SYBR Premix Ex Taq ${ }^{\mathrm{TM}}$ (Takara Bio, Inc.) in a 20- $\mu \mathrm{l}$ reaction mixture containing $1 \mu \mathrm{l}$ of each cDNA and $0.2 \mu \mathrm{M}$ of each pair of primers. Samples were preheated at $95^{\circ} \mathrm{C}$ for $30 \mathrm{sec}$. RT-PCR conditions consisted of 40 cycles of $5 \mathrm{sec}$ at $95^{\circ} \mathrm{C}$ and $34 \mathrm{sec}$ at $60^{\circ} \mathrm{C}$. The dissociation stage consisted of $15 \mathrm{sec}$ at $95^{\circ} \mathrm{C}, 1 \mathrm{~min}$ at $60^{\circ} \mathrm{C}$ and $15 \mathrm{sec}$ at $95^{\circ} \mathrm{C}$. The pairs of primers are shown in Table II. GAPDH was used as an endogenous control. The thermocycling conditions and the method of quantification were performed as previously described (31).

Western blotting. Total proteins were extracted from different cell stages (day 11 or day 20 after induction) using radioimmunoprecipitation assay buffer and a cocktail mixture (Thermo Fisher Scientific, Inc.). The concentration of protein was measured using the Pierce Bicinchoninic Acid Protein assay kit (Thermo Fisher Scientific, Inc.). Protein $(30 \mu \mathrm{g})$ was subjected to a $10 \%$ resolving gel for electrophoresis. The SDS-polyacrylamide gel electrophoresis was performed at $80 \mathrm{~V}$ first for $20 \mathrm{~min}$, and then at $100 \mathrm{~V}$ for $80 \mathrm{~min}$. Next, the protein was transferred to polyvinylidene difluoride membranes at $276 \mathrm{~mA}$ for $150 \mathrm{~min}$ using a semi-dry transfer apparatus (Bio-Rad Laboratories, Inc., Hercules, CA, USA). The blot membranes were washed in Tris-buffered saline with $0.1 \%$ Tween-20 (TBST) and blocked with 5\% BSA in TBST for $1 \mathrm{~h}$ at room temperature. The membranes were then incubated with primary antibodies at $4{ }^{\circ} \mathrm{C}$ with agitation overnight. Following this, the membranes were washed in TBST three times for $5 \mathrm{~min}$ each time, incubated with their corresponding secondary antibodies for $2 \mathrm{~h}$, and rinsed in TBST 
A
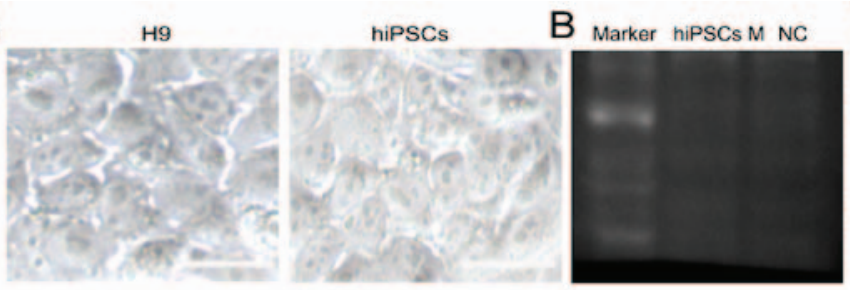

C

$\mathrm{D}$
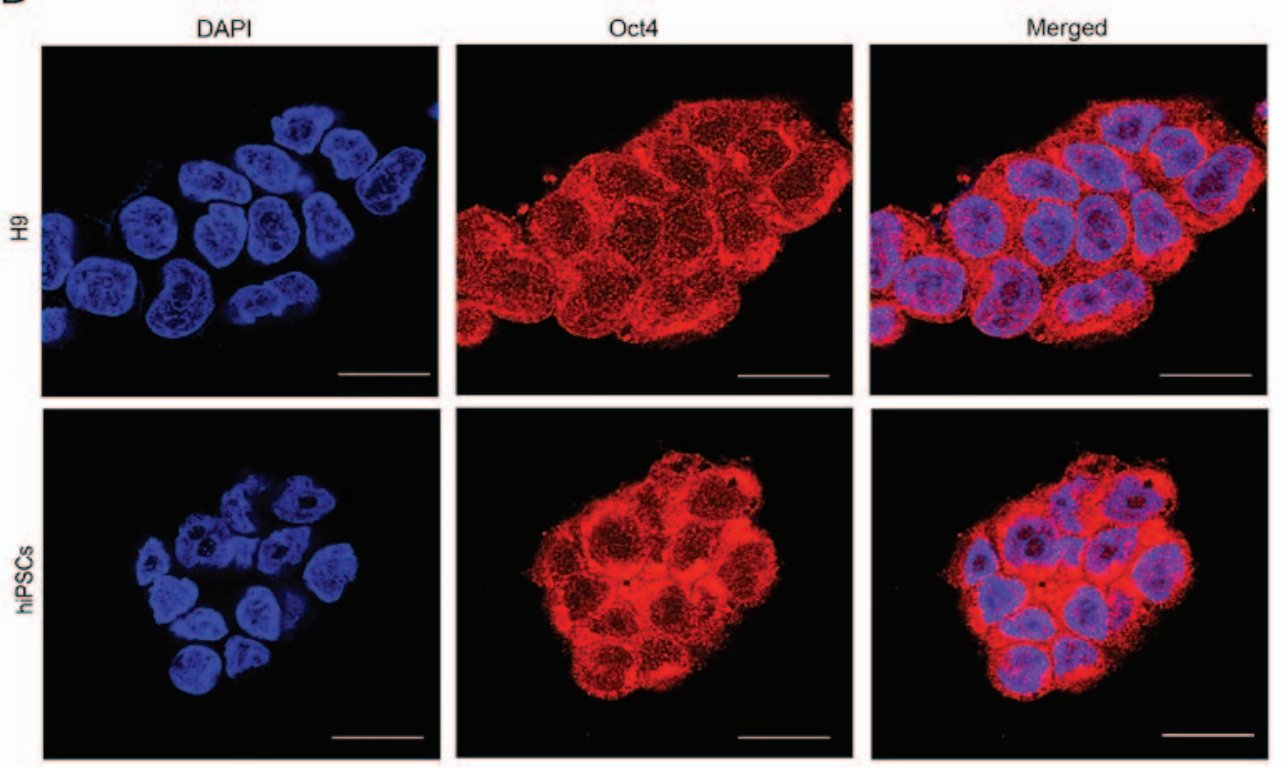

Figure 1. Pluripotency detection of hiPSCs. (A) The structure of hiPSCs and human H9 embryonic stem cell line under bright field microscopy Scale bar, $20 \mu \mathrm{m}$. (B) RT-PCR showing no mycoplasma contamination. (C) The mRNA expression of pluripotent genes OCT4, NANOG, SOX2 and LIN28 in hiPSCs were detected by RT-qPCR, with H9 used as a control. Results are presented as the mean \pm standard deviation. (D) The protein expression of OCT4 in hiPSCs and the H9 cell line, observed using immunofluorescence. Scale bar, $20 \mu \mathrm{m}$. hiPSCs, human induced pluripotent stem cells; RT-PCR, reverse transcription-quantitative polymerase chain reaction; NANOG, Nanog homeobox; OCT4, POU class 5 homeobox 1; LIN28, lin-28 homolog A; SOX2, SRY-box 2; DAPI, 4',6-diamidino-2-phenylindole.

three times again. Enhanced chemiluminescence substrate was then applied (Thermo Fisher Scientific, Inc.). The value of the chemiluminescence was recorded and the band density was quantified using Image J software. Primary antibodies used in this study were MAP2 (4542; 1:1,000 dilution; Cell Signaling Technology, Inc.), TUJ1 (T2200; 1:1,000 dilution; Sigma-Aldrich; Merck KGaA), AKT (9272; 1:1,000 dilution) and p-AKT (4060; 1:1,000 dilution) (both Cell Signaling Technology, Inc.). Secondary antibodies used in this study were horseradish peroxidase-conjugated goat anti-rabbit antibody (7074; 1:5,000 dilution; Cell Signaling Technology, Inc.).

Cell Counting kit-8 (CCK-8) assay. The CCK-8 method was used to detect the viability of neurons differentiated from hiPSC-derived NPCs on culture day 20 in each differentiation group. Briefly, 20-day differentiated cells were seeded on 96-well plates at a density of 5,000/well, and then incubated with $10 \mu \mathrm{l} \mathrm{CCK-8} \mathrm{(KeyGen} \mathrm{Biotech} \mathrm{Co.,} \mathrm{Ltd.,} \mathrm{Nanjing,} \mathrm{China)}$ in a total volume of $100 \mu \mathrm{l}$ culture medium for 2 to $4 \mathrm{~h}$ at $37^{\circ} \mathrm{C}$. Next, the 96-well plate was placed on an enzyme standard instrument (ELx800; BioTek Instruments, Inc., Winooski, VT, USA). The plate was read at a wavelength of $450 \mathrm{~nm}$. The neuron control differentiation medium was used as the control.

Apoptosis and flow cytometry analyses. Neurons differentiated from hiPSC-derived NPCs on culture day 20 in the control differentiation group and the LIF-positive differentiation group were subjected to standard procedure of cell apoptosis analysis. Cells $\left(1 \times 10^{5}\right)$ were fixed and labeled with Annexin V-FITC, $45 \mathrm{~min}$ at room temperature and propidium iodide using the Annexin V-FITC and propidium iodide using the Annexin-V-FLUOS staining kit (BD Biosciences, San Jose, CA, USA) according to the manufacturer's protocols, followed by flow cytometry analysis. The Annexin V-positive cells were counted as apoptotic cells.

Statistical analysis. All the experiments were independently repeated at least three times, and statistical analysis was performed using the SPSS 17.0 software (SPSS, Inc., Chicago, IL, USA). The data are expressed as the mean \pm standard deviation. Pairwise comparisons between groups were performed using the independent sample t-test and one-way analysis of variance followed by pairwise $t$ tests. The correction test we used here is Bonferroni's correction. $\mathrm{P}<0.05$ was considered to indicate a statistically significant difference.

\section{Results}

hiPSCs exhibit similar characteristics to the H9 embryonic stem cell line. hiPSCs exhibited the similar morphological characteristics as the H9 embryonic stem cell line (Fig. 1A). Mycoplasma contamination detection showed that the hiPSCs 


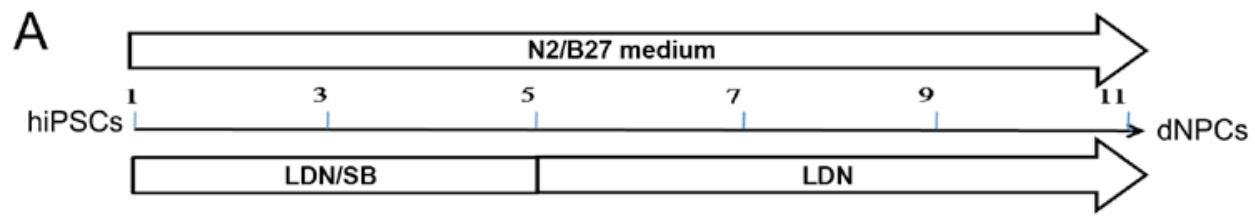

Induction medium: DMEM/F12/Neurobasal (1:1) + 1\% N2 + 2\% B27 medium

B

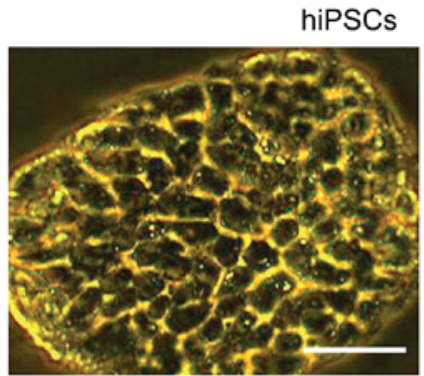

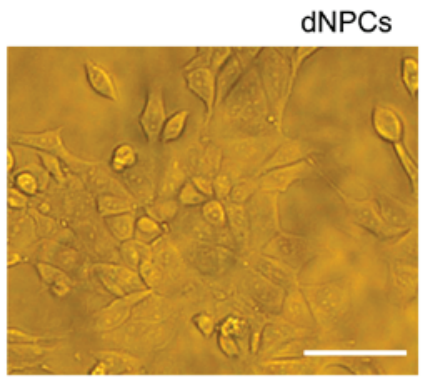

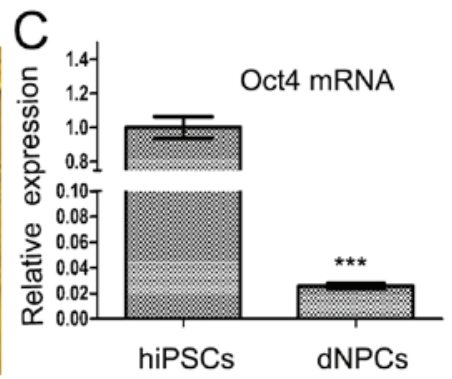

D
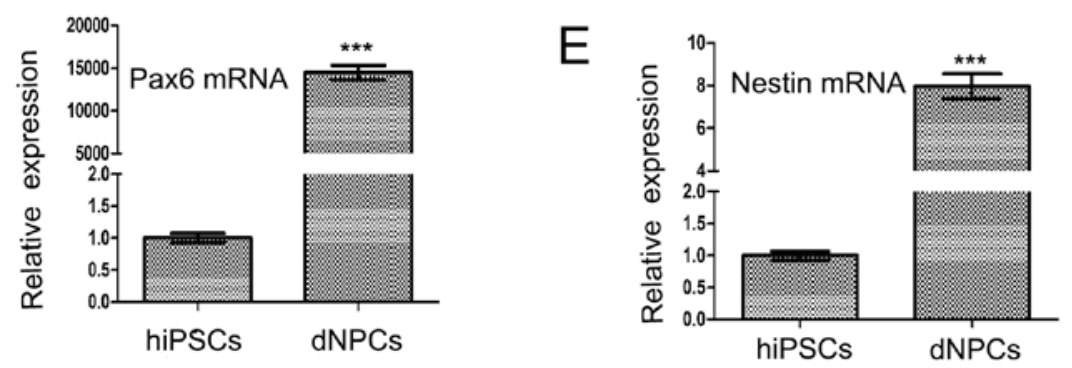

Figure 2. Generation of NPCs from hiPSCs. (A) The time course of NPC induction from hiPSCs. (B) The morphology of hiPSCs and hiPSC-derived NPCs on culture day 11 under bright field microscopy (scale bar, $20 \mu \mathrm{m}$ ). (C) The mRNA expression of $O C T 4$ in hiPSCs and derived NPCs on culture day 1 was detected by RT-qPCR. (D and E) The relative mRNA expression of NES and PAX6 in derived NPCs and hiPSCs was detected by RT-qPCR on culture day 11 . Results are presented as the mean \pm standard deviation. ${ }^{* * *} \mathrm{P}<0.001$. NPCs, neural precursor cells; dNPCs, derived NPCs; hiPSCs, human induced pluripotent stem cells; RT-PCR, reverse transcription-quantitative polymerase chain reaction; DMEM, Dulbecco's modifed Eagle's medium; OCT4, POU class 5 homeobox 1; PAX6, paired box 6 .

were not contaminated by mycoplasma (Fig. 1B). RT-qPCR analysis showed that the relative mRNA expression of the pluripotent markers in hiPSCs, including OCT4, Nanog homeobox, SRY-box 2 and lin-28 homolog A, showed no significant differences with the control H9 cell line (Fig. 1C). As with the H9 cells, the hiPSCs cells were also OCT4-positive, as shown in the immunofluorescence images (Fig. 1D).

A large proportion of hiPSC-derived NPCs can be harvested after neural induction. In the present study, hiPSCs were transformed into NPCs by adding BMP signaling inhibitor LDN193189 and TGF- $\beta$ signaling inhibitor SB431542 into the N2/B27 basal culture medium. The transformation of NPCs was finished after 11 days of induction. The induction time course is shown in Fig. 2A. The derived cells have different morphological characteristics compared with the hiPSCs (Fig. 2B). The relative mRNA expression of pluripotent gene OCT4 was significantly downregulated in the derived NPCs compared with that in the hiPSCs (Fig. $2 \mathrm{C} ; \mathrm{P}<0.001$ ). By contrast, the mRNA expression of NPC markers, including nestin (NES) and $P A X 6$, were significantly upregulated in the derived NPCs compared with that in the hiPSCs (Fig. 2D and E; both $\mathrm{P}<0.001)$. Furthermore, immunofluorescence data clearly showed that the Nestin and PAX6 proteins were highly expressed in the derived NPCs, but rarely expressed in the hiPSCs (Fig. 3A and B).

LIF upregulates the expression of neuronal markers TUJ1 and MAP2 during the differentiation period. Following the derivation of NPCs from hiPSCs, the derived NPCs were differentiated into neurons. The normal differentiation medium differentiation group was used as the control differentiation group. The differentiation time course is shown in Fig. 4A. The effect of LIF on neuronal differentiation was tested on culture day 20. The neuronal markers TUJ1 and MAP2 were detected by immunofluorescence methods (Figs. 4B and 5B). The relative fluorescence intensity analysis by ImageJ revealed that the expression of TUJ1 and MAP2 in the LIF $(5 \mathrm{ng} / \mathrm{ml})$ positive differentiation group was significantly higher than that of the control differentiation group (Figs. $4 \mathrm{C}$ and $5 \mathrm{C}$; both $\mathrm{P}<0.01)$. The relative mRNA expression of $T U J 1$ and $M A P 2$ in the LIF-positive differentiation group was significantly higher than that in the control differentiation group (Figs. 4D and 5D; both $\mathrm{P}<0.01$ ). The protein expression of TUJ1 and MAP2 in the LIF-positive differentiation group was significantly higher than that in the control differentiation group too (Figs. 4E and $\mathrm{F}$ and $5 \mathrm{E}$ and $\mathrm{F}$; both $\mathrm{P}<0.01$ ). LIF concentration test experiments showed that adding $5 \mathrm{ng} / \mathrm{ml} \mathrm{LIF} \mathrm{to} \mathrm{the} \mathrm{control}$ 

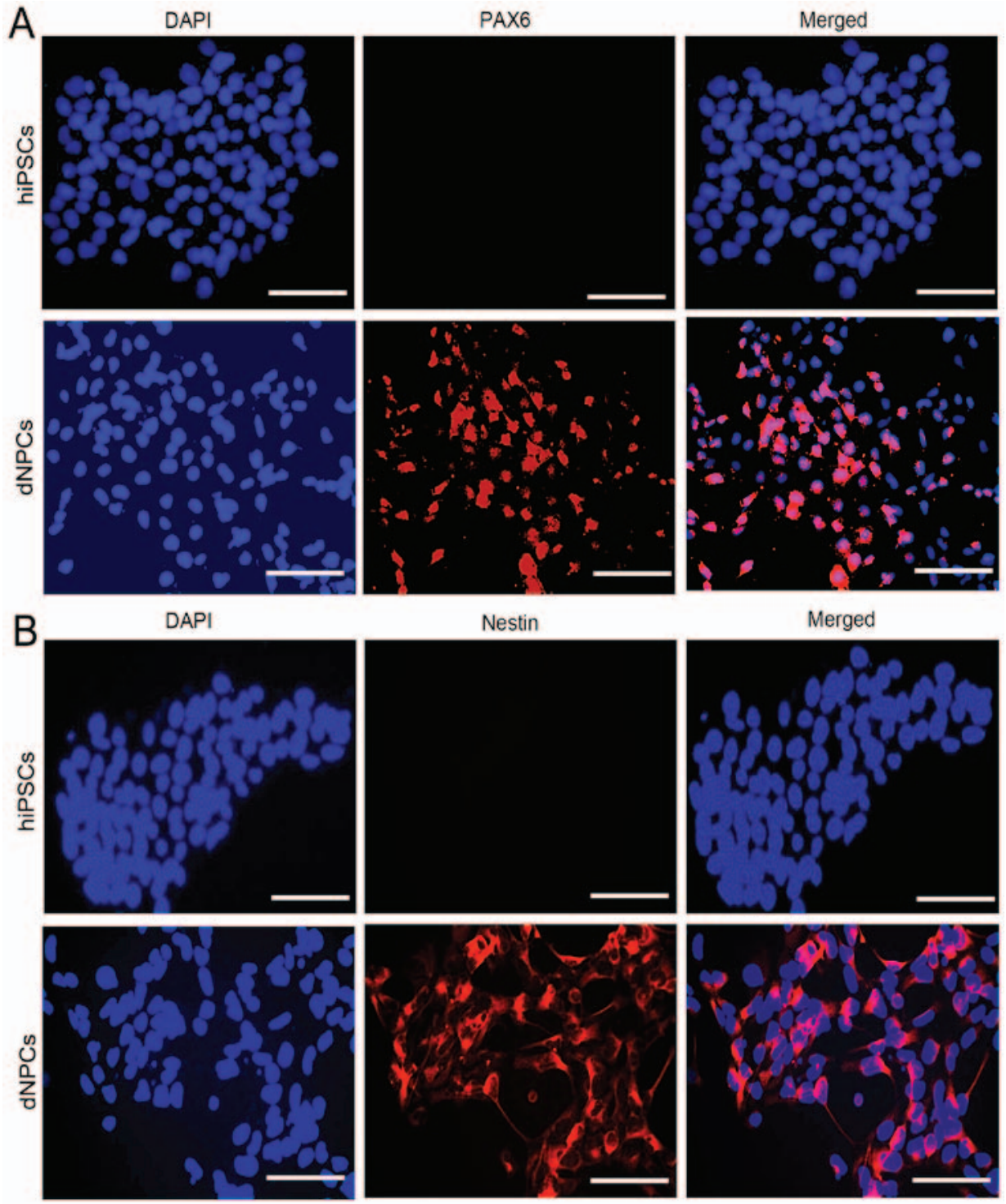

Figure 3. Detection of Nestin and PAX6 in derived NPCs and hiPSCs by immunofluorescence. (A) The expression of NPC marker PAX6 in the derived NPCs on culture day 11 and in hiPSCs was measured by immunofluorescence. (B) The expression of NPC marker Nestin in the derived NPCs on culture day 11 and in hiPSCs was measured byimmunofluorescence. Scale bar, $20 \mu \mathrm{m}$. DAPI, 4',6-diamidino-2-phenylindole; dNPCs, derived neural precursor cells; hiPSCs, human induced pluripotent stem cells; PAX6, paired box 6.

differentiation medium resulted in the strongest mRNA expression of TUJ1 and MAP2, as detected by RT-qPCR on culture day 20 (Fig. 5A).

LIF improves cell activity during differentiation. On culture day 20 , the cells were observed under light microscope and the cell state (structure under the optical microscope) was found to be better in the LIF-positive differentiation group than that in the control group (Fig. 6A). The number of differentiated neurons in the LIF-positive differentiation group was greater than that of the control group counted on culture day 20 (Fig. 6B; $\mathrm{P}<0.05)$. The viability of the cells was detected by CCK- 8 method and it was found that the viability of neurons in the LIF-positive differentiation group was greater than that in the control group on culture day 20 (Fig. 6C; P<0.01). Apoptosis and flow cytometry analyses showed that there were significantly less apoptotic cells in the LIF differentiation group than in the control differentiation group (Fig. 6D; $\mathrm{P}<0.05$ ).
LIF influences the mRNA expression of inflammatory cytokines. Inflammation is a primary pathological driving force of a number of neurodegenerative disorders (32); in the process of nervous system injury, pro-inflammatory cytokines (IL-1 $\beta$ and TNF- $\alpha$ ) are robustly released, which may affect normal NPC differentiation, and lead to a vast number of astrocytes and a diminished neural population. In the present study, the expression of inflammation-related factors was checked by RT-qPCR on culture day 20 when neurons were differentiated from derived NPCs. The results showed that the expression of the pro-inflammatory cytokines, including IL- $1 \alpha$ and TNF- $\alpha$, was decreased, whilst the expression of anti-inflammatory cytokines, including IL-10 and TGF- $\beta$, was increased in the LIF-positive differentiation group compared with that in the control differentiation group (Fig. $6 \mathrm{E}$ and $\mathrm{F}$; all $\mathrm{P}<0.05$ ).

LIF upregulates the expression of $p$-AKT. A previous study showed that the inflammatory reaction could affect the 


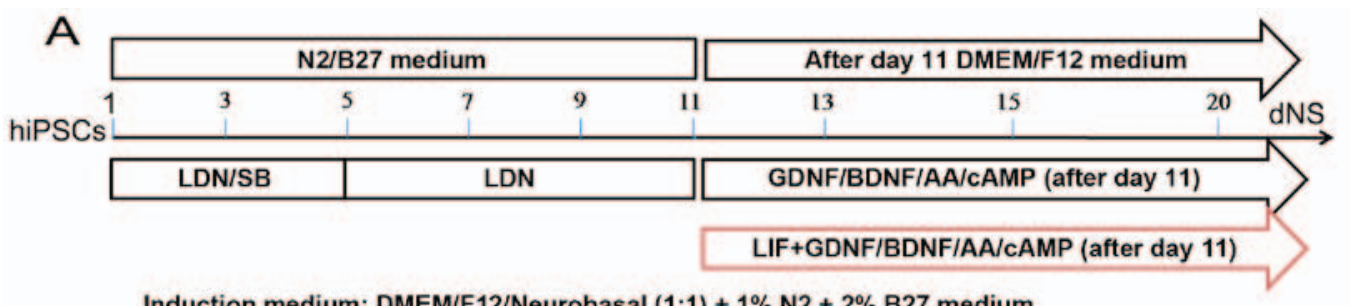

Induction medium: DMEM/F12/Neurobasal (1:1) + 1\% N2 + $2 \%$ B27 medium

Differentiation medium: DMEM/F12 + $1 \% \mathrm{~N} 2+2 \% \mathrm{~B} 27$ medium

B
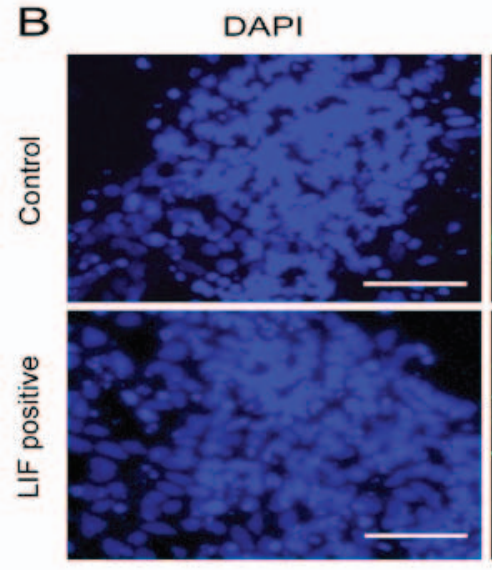

C

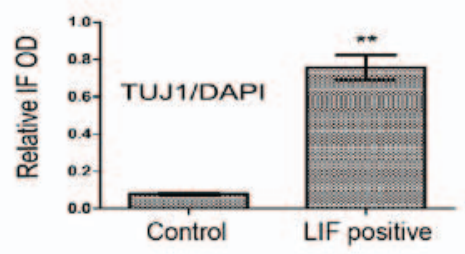

$\mathrm{E}$

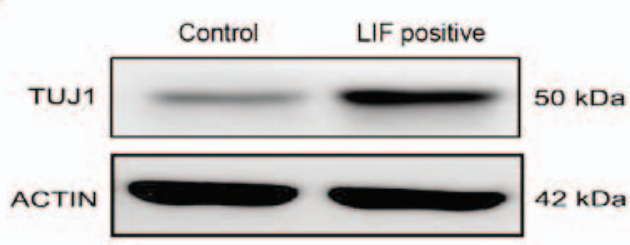

TUJ1
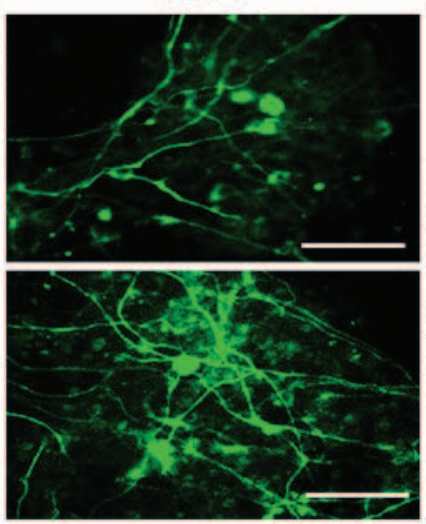

Merged

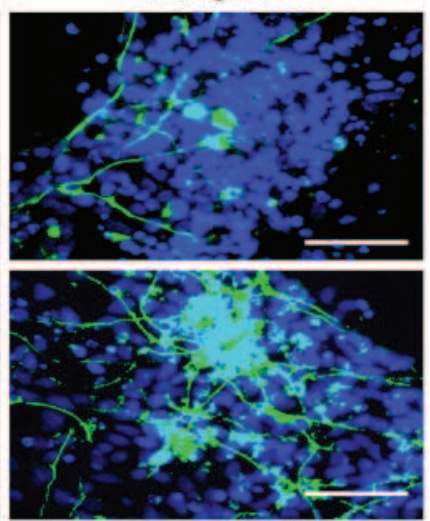

F

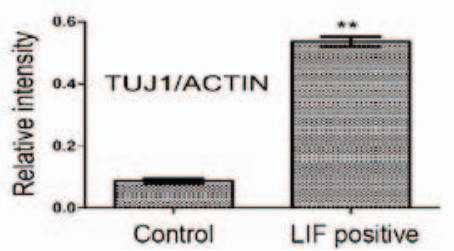

Figure 4. LIF improves the expression of TUJ1. (A) The time course of neuronal differentiation in the presence or absence of LIF. (B) The expression of TUJ1 (green) and DAPI (blue) was observed by immunofluorescence on culture day 20 in the LIF differentiation group and the control group. (C) The relative fluorescence intensity value of TUJ1 was qualified by ImageJ software and the data is expressed as the relative OD value (TUJ1/DAPI). (D) The relative mRNA expression of TUJ1 was detected by reverse transcription-quantitative polymerase chain reaction in the LIF differentiation and control groups. (E) The TUJ1 protein expression was detected by western blotting in the LIF differentiation and control groups. (F) The relative band intensity of TUJ1 was qualified by ImageJ software. Results are presented as the mean \pm standard deviation. ${ }^{* *} \mathrm{P}<0.01$. Scale bar, $20 \mu \mathrm{m}$. GDNF, glial cell line-derived neurotrophic factor; BDNF, brain-derived neurotrophic factor; DMEM, Dulbecco's modifed Eagle's medium; AA, ascorbic acid; cAMP, cyclic adenosine monophosphate; LIF, leukocyte inhibitory factor; DAPI, 4',6-diamidino-2-phenylindole; TUJ1, neuron-specific class III $\beta$-tubulin; IF, immunofluorescence; OD, optical density.

PI3K/AKT signaling pathway (33), and the activation of the $\mathrm{PI} 3 \mathrm{~K} / \mathrm{AKT}$ signaling pathway could be involved in the inflammatory reaction. The present study found that in the LIF-positive differentiation group, p-AKT, the key composition factor of PI3K/AKT, was significantly increased (Fig. 6G and H; $\mathrm{P}<0.01)$. This finding revealed that the improved neuronal differentiation may be mediated by the PI3K/AKT signaling pathway.

The effect of LIF could be prevented by PI3K/AKT inhibitor LY294002. In order to confirm the effect of LIF on neuron differentiation was mediated by the activation of the PI3K/
AKT signaling pathway. PI3K/AKT inhibitor LY294002 was used. Following the addition of LY294002 during the differentiation period, the protein expression of TUJ1 and MAP2 was downregulated compared with that in the LIF differentiation group (Fig. 7A and $\mathrm{B}$; both $\mathrm{P}<0.05$ ). Additionally, the expression of $\mathrm{p}$-AKT was downregulated compared with that in the LIF-positive group (Fig. 7C and D; $\mathrm{P}<0.05$ ). Furthermore, the mRNA expression of inflammatory cytokines IL-10, TGF- $\beta$, IL- 1 and TNF- $\alpha$ was returned to a more normal level compared with that in the LIF-positive differentiation group (Fig. 7E and F; all $\mathrm{P}<0.01$ ). The number and the viability of differentiated neurons decreased after the addition of 

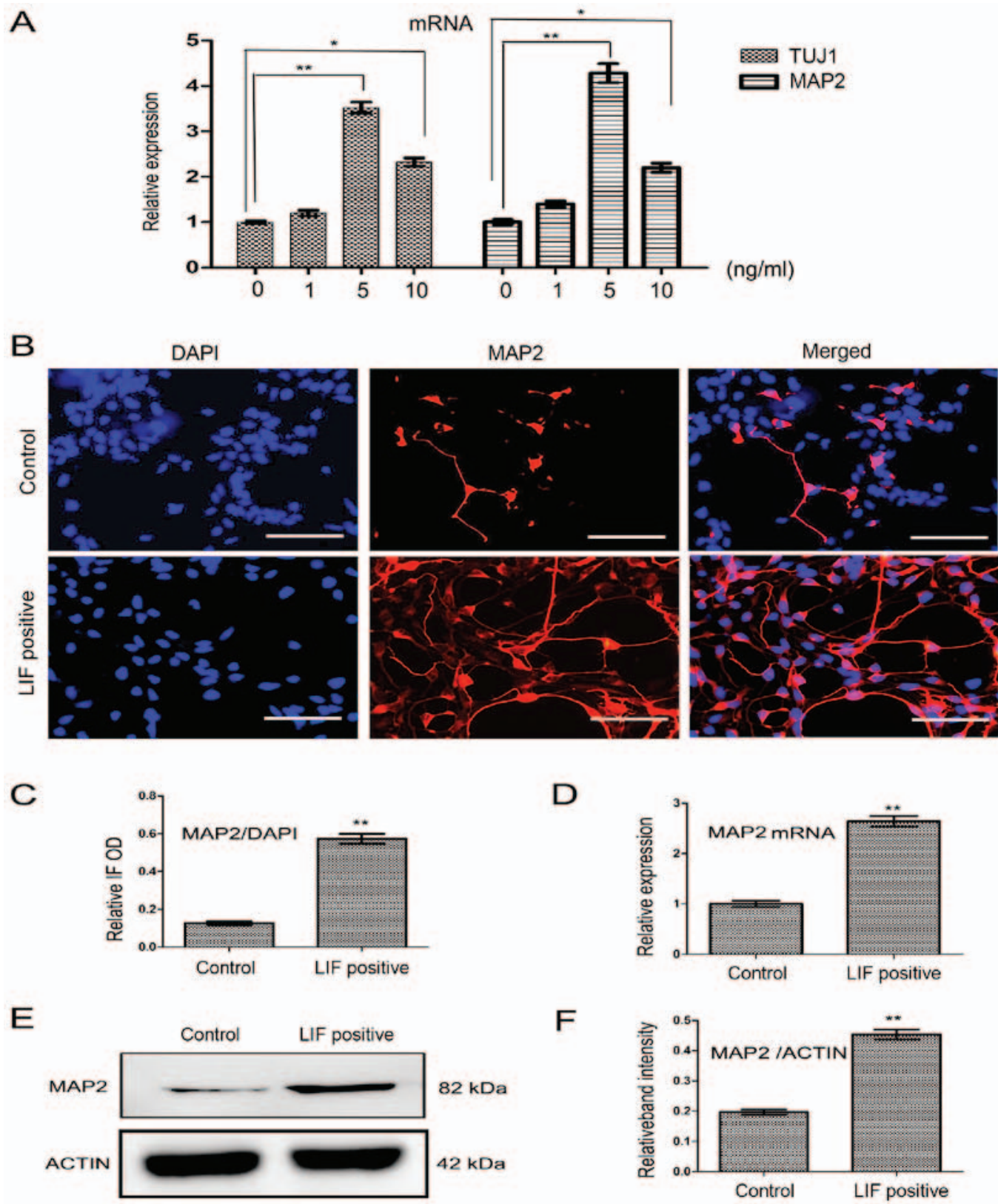

Figure 5. LIF enhances the expression of MAP2. (A) The relative mRNA expression of TUJ1 and MAP2 on culture day 20 in the different LIF concentration treated groups. Results showed that, in the $5 \mathrm{ng} / \mathrm{ml}$ LIF differentiation group, the mRNA expression of TUJ1 and MAP2 was strongest. (B) The protein expression of MAP2 (red) and DAPI (blue) on culture day 20 was observed by immunofluorescence. (C) The relative fluorescence intensity of MAP2 was qualified using ImageJ and the data are expressed as the relative OD value (MAP2/DAPI). (D) The relative mRNA expression of MAP2 was detected by reverse transcription-quantitative polymerase chain reaction in the LIF differentiation group and the control group. (E) The MAP2 protein expression in the LIF differentiation group and the control group was detected by western blotting. (F) The relative band intensity of MAP2 protein was qualified by ImageJ software. Results are presented as the mean \pm standard deviation. " $\mathrm{P}<0.05$ and ${ }^{* * *} \mathrm{P}<0.01$. Scale bar, $20 \mu \mathrm{m}$. MAP2, microtubule-associated protein 2; TUJ1, neuron-specific class III $\beta$-tubulin; DAPI, 4',6-diamidino-2-phenylindole; IF, immunofluorescence; OD, optical density; LIF, leukocyte inhibitory factor.

LY294002 compared with that in the LIF-positive differentiation group (Fig. $7 \mathrm{G}$ and $\mathrm{H}$; both $\mathrm{P}<0.01$ ).

The effect of LIF could be prevented by PI3K/AKT inhibitor wortmannin but not rapamycin. In order to confirm the effect of LIF on neuron differentiation was mediated by the PI3K/AKT signaling pathway. Another PI3K/AKT signaling pathway inhibitor, wortmannin, and an mTOR signaling inhibitor, rapamycin, were used here. Following the addition of wortmannin to the LIF-positive differentiation group, it was found that the changes in the protein expression of TUJ1 and MAP2 was similar to that found following the addition of LY294002 (Fig. 8A and B; P<0.05). However, this phenomenon was not found in the rapamycin-treated group (Fig. 8C and D; $\mathrm{P}<0.05)$. The changes in mRNA expression of inflammatory cytokines IL-10, TGF-B, IL-1 and TNF- $\alpha$ in the wortmannin-treated group were similar to those found in the LY294002-treated group, compared with the LIF-positive differentiation group (Fig. $8 \mathrm{G}$ and $\mathrm{H} ; \mathrm{P}<0.05$ ). However, this phenomenon was not found in the rapamycin-treated differentiation group compared with the LIF-positive differentiation group (Fig. 8I and J). 



E

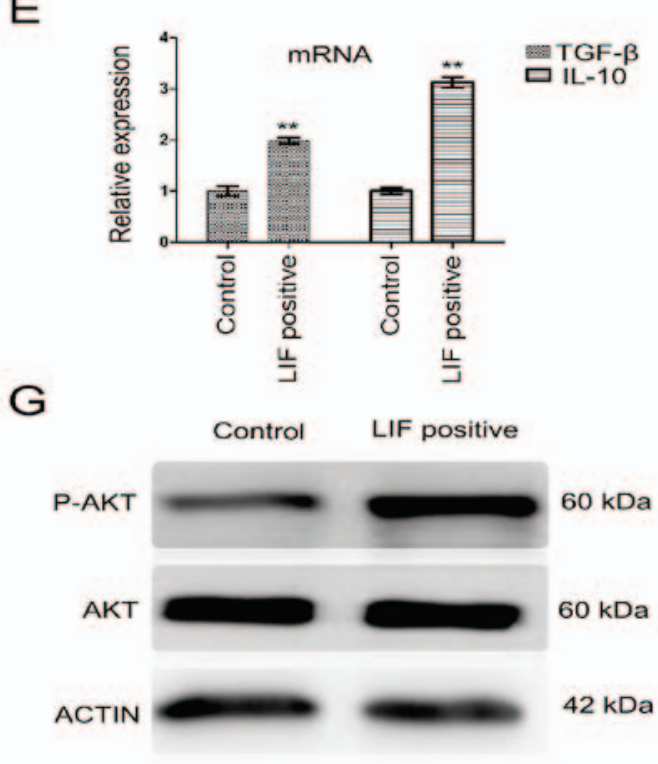

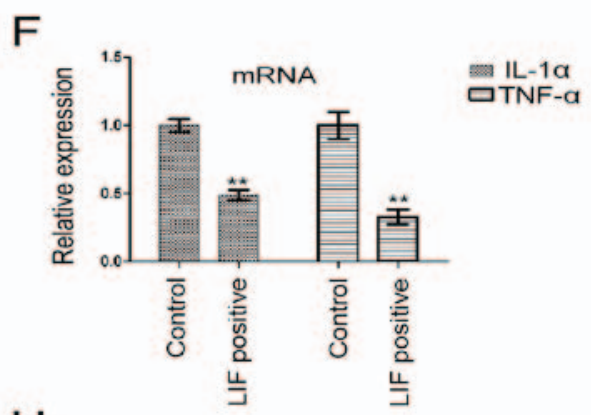

$\mathrm{H}$

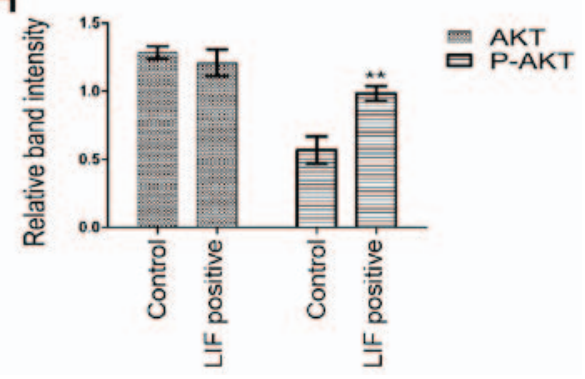

Figure 6. LIF affects the cell viability and the mRNA expression of inflammatory cytokines. (A) The neurons differentiated in LIF differentiation and control groups under bright field microscopy on culture day 20. (B) The cell number was counted on culture day 20. (C) The cell viability was measured by cell counting kit-8 method on culture day 20. (D) Cells on culture day 20 were labeled with Annexin V-FITC and PI. Cells in the R3 area were counted as apoptotic cells. (E) The relative mRNA expression of the anti-inflammatory cytokines TGF- $\beta$ and IL-10 in LIF differentiation and control groups, and (F) the pro-inflammatory cytokines IL-1 $\alpha$ and TNF- $\alpha$ on culture day 20 was detected by reverse transcription-quantitative polymerase chain reaction. (G) The protein expression of AKT and p-AKT was analyzed by western blotting. (H) The relative band intensity of AKT and p-AKT was qualified by ImageJ software. Results are presented as the mean \pm standard deviation. ${ }^{*} \mathrm{P}<0.05$ and ${ }^{* *} \mathrm{P}<0.01$. Scale bar, $20 \mu \mathrm{m}$. LIF, leukocyte inhibitory factor; FITC, fluorescein isothiocyanate; PI, propidium iodide; PE, phycoerythrin; TGF- $\beta$, transforming growth factor- $\beta$; IL, interleukin; TNF- $\alpha$, tumor necrosis factor- $\alpha$; p-AKT, phosphorylated protein kinase B.

\section{Discussion}

The transformation of hiPSCs into neural cells provides one source of stem cells for the cell therapy of neurodegenerative diseases, including Parkinson's disease and Alzheimer's disease (34). A high derivation quality and proportion of NPCs from hiPSCs is a crucial step in the whole cell therapy procedure. There are several induction methods to convert the pluripotent stem cells into NPCs, relying on co-culture with stromal cells or initiating by the formation of embryoid bodies $(35,36)$. However, the low conversion efficiency, the contamination of miscellaneous cells and the complexity of experimental operation has made these methods impractical. In the present study, the dual inhibition method of neural induction used by Chambers et al (37) was meliorated using monolayer culture and N2/B27 medium to induce neuron differentiation. During the induction period, the BMP inhibitor LDN193189 and the TGF- $\beta$ inhibitor SB431542 were used as the induction factor. Under these conditions, a high proportion of cells were converted into nerve cells, which were defined as NPCs, expressing Nestin and PAX6. This may be attributed to the induction inhibition of endodermal and mesodermal cells by LDN193189 and SB431542. Neuronal differentiation following successful induction of NPCs is another key step for 
A

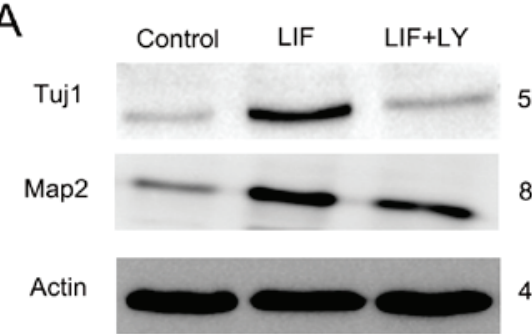

C

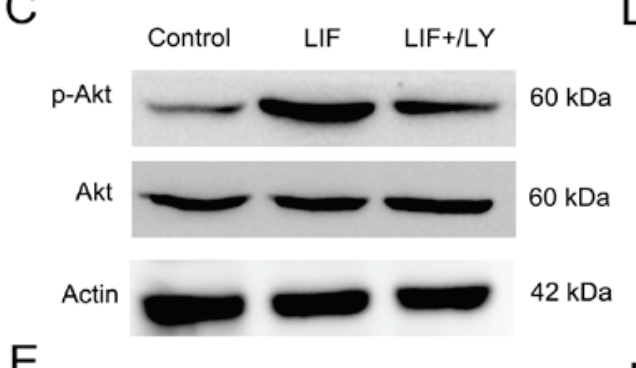

E

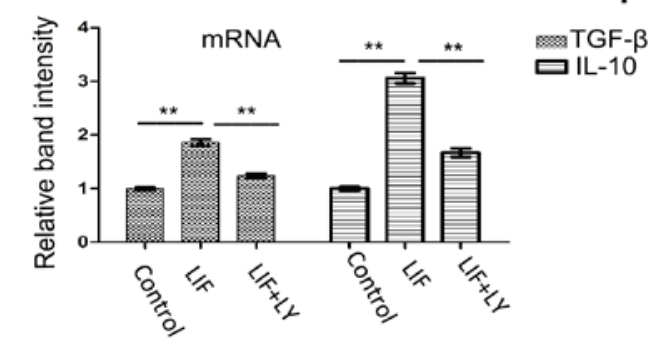

G

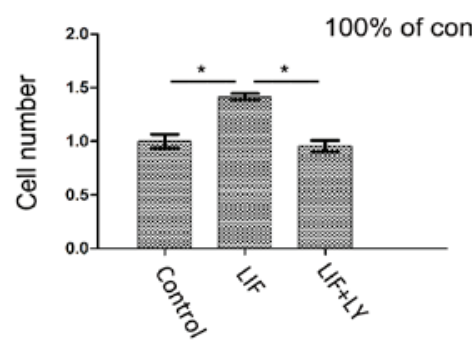

B

D

$\mathrm{F}$

$\mathrm{H}$
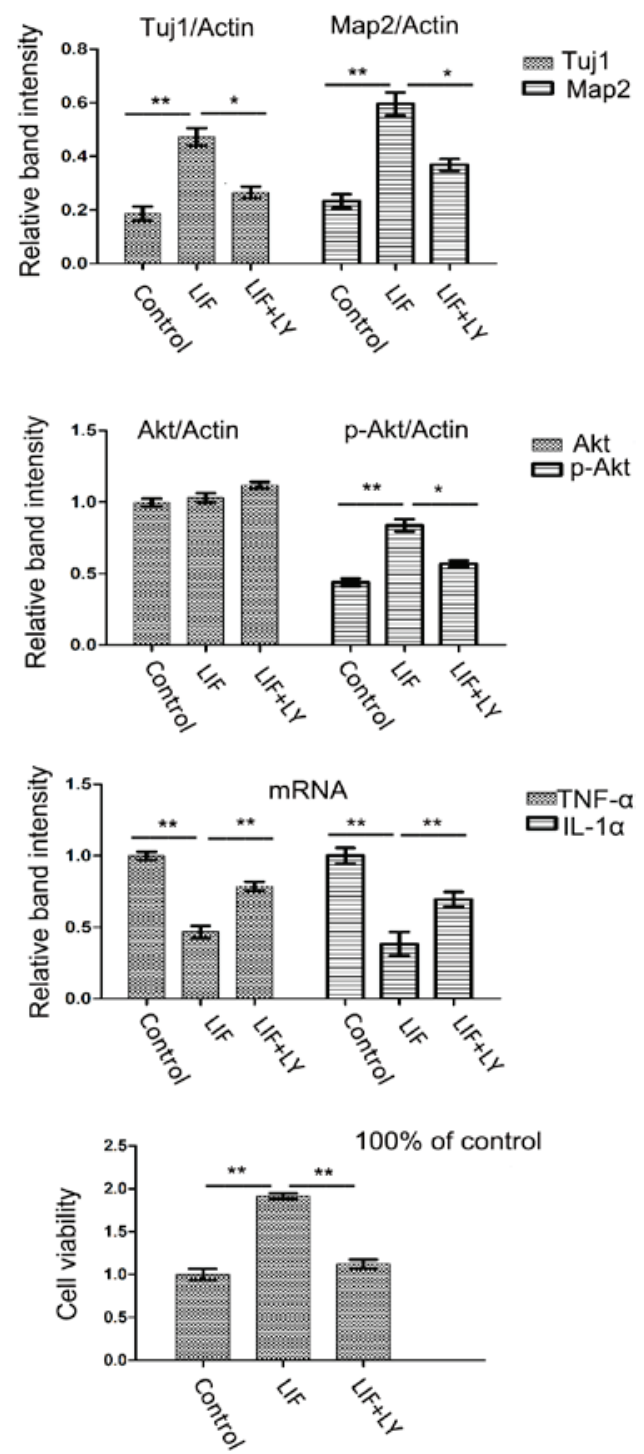

Figure 7. Inhibition of phosphatidylinositol 3-kinase/AKT by LY294002 prevents the LIF-induced changes in the expression of neuronal markers and converts the mRNA expression of inflammatory cytokines. (A) The protein expression of TUJ1 and MAP2 was examined on culture day 20 in control, LIF and LIF with LY294002 differentiation group cells by western blotting. (B) The relative band intensity of (A) was qualified by ImageJ software. (C) The protein expression of AKT and p-AKT was detected on culture day 20 in control, LIF and LIF with LY294002 differentiation group cells by WB. (D) The relative band intensity of (C) was qualified by ImageJ software. (E) The relative mRNA expression of anti-inflammatory factors TGF- $\beta$ and IL-10 on culture day 20 in control, LIF and LIF with LY294002 differentiation group cells by RT-qPCR. (F) The relative mRNA expression of pro-inflammatory factors TNF- $\alpha$ and IL-1 $\alpha$ on culture day 20 in control, LIF and LIF with LY294002 differentiation group cells were detected by RT-qPCR. (G) The number of neurons counted on culture day 20 in control, LIF and LIF with LY294002 differentiation group cells. (H) The cell viability was detected on culture day 20 in control, LIF and LIF with LY294002 differentiation group cells by cell counting kit- 8 . Results are presented as the mean \pm standard deviation. ${ }^{*} \mathrm{P}<0.05$ and ${ }^{* * *} \mathrm{P}<0.01$. p-AKT, phosphorylated protein kinase B; LY, LY294002; LIF, leukocyte inhibitory factor; MAP2, microtubule-associated protein 2 ; TUJ1, neuron-specific class III $\beta$-tubulin; TGF- $\beta$, transforming growth factor- $\beta$; IL, interleukin; RT-qPCR, reverse transcription-quantitative polymerase chain reaction; TNF- $\alpha$, tumor necrosis factor- $\alpha$.

the cell treatment of diseases of the nervous system. However, the low differentiation ratio and poor survival state require improvement.

LIF, a member of the IL-6 superfamily, acts through binding to its specific receptor, LIFR. It conscribes gp130 and then an affinity receptor complex is formed, which can activate the downstream pathways, including the PI3K/AKT, ERK1/2, JAK/STAT3 and mTOR signaling pathways (12-15). LIF can regulate cell proliferation, differentiation and phenotype; its main function is inhibiting the differentiation of mESCs and promoting the proliferation of muscle cells. Under certain conditions, LIF can promote a neonatal rat dorsal root ganglion neuronal phenotype to change from the adrenergic type to the cholinergic type. Therefore, LIF is also known as cholinergic neuronal differentiation factor (20). In addition, LIF can promote the survival of cells differentiated from the transplanted neural crest (38). Laterza et al (39) revealed that transplanted mouse iPSC-derived NPCs exert neuroprotection through the secretion of LIF, which promotes the survival and differentiation capacity of oligodendrocytes. However, the in vitro effect of LIF on neuron differentiation is rare. In the present study, a concentration of $5 \mathrm{ng} / \mathrm{ml} \mathrm{LIF}$ was added to the 
A

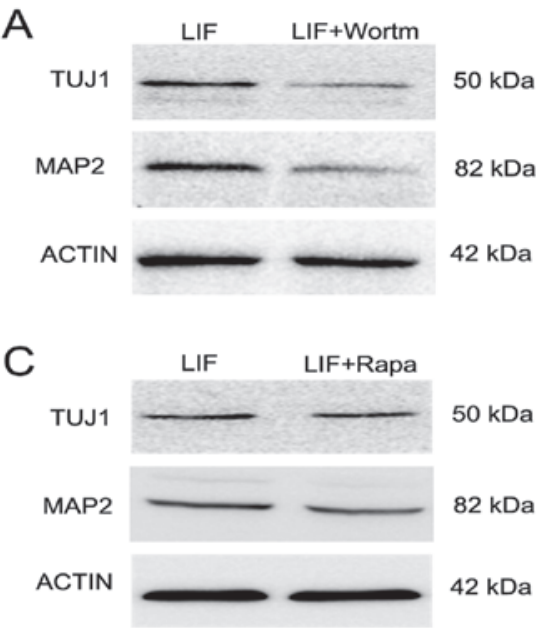

E

$$
\text { E }
$$

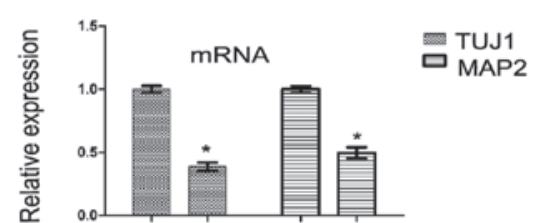

G

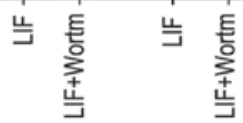
G

I

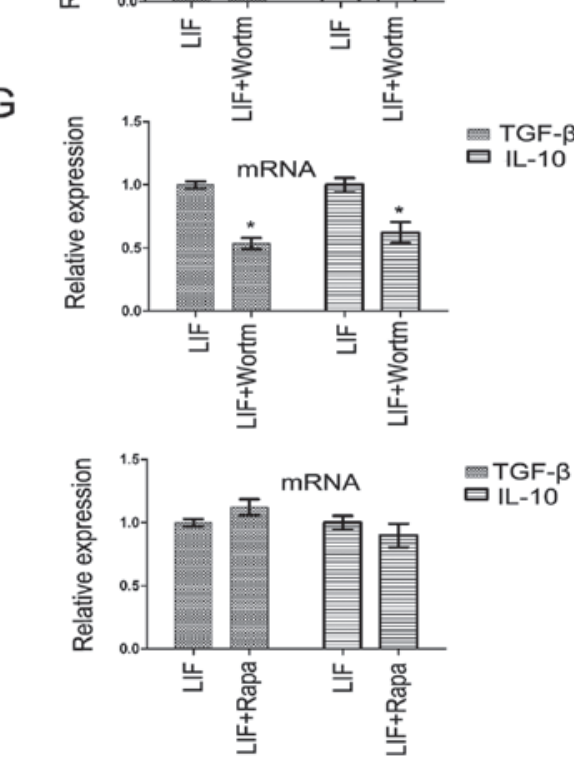

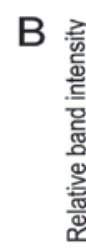

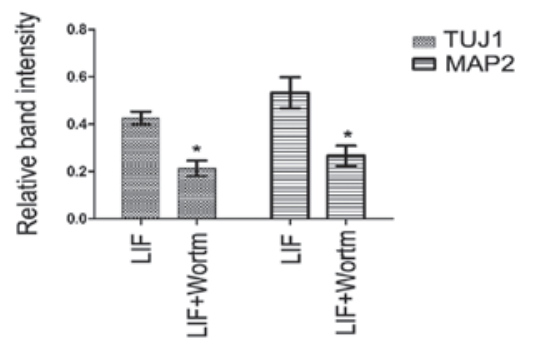

D

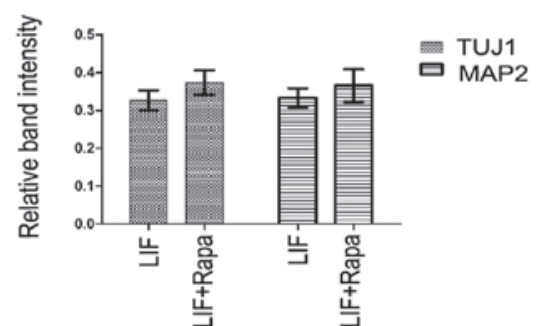

$F$.



$\mathrm{H}$



$J$

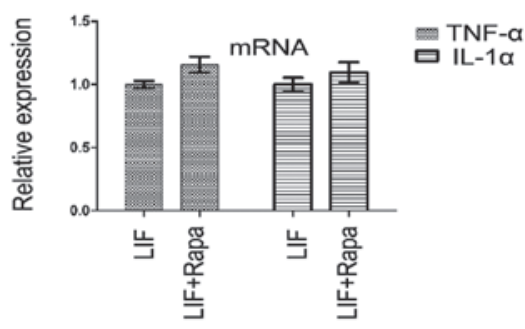

Figure 8. Inhibition of phosphatidylinositol 3-kinase/AKT by wortmannin could also prevent the LIF-induced changes in the expression of neuronal markers and the mRNA expression of inflammatory cytokines, but this effect was not found in the rapamycin differentiation group. (A and B) The protein expression of TUJ1 and MAP2 was examined by western blotting in LIF and LIF combined with wortmannin differentiation groups. The relative band intensity of TUJ1 and MAP2 was qualified by ImageJ software. (C and D) The protein expression of TUJ1 and MAP2 was detected by western blotting in LIF and LIF combined with rapamycin differentiation groups. The relative band intensity of TUJ1 and MAP2 was qualified by ImageJ software. (E) The relative mRNA expression of TUJ1 and MAP2 on culture day 20 was detected by RT-qPCR in LIF and LIF combined with wortmannin differentiation groups. (F) The relative mRNA expression of TUJ1 and MAP2 on culture day 20 was detected by RT-qPCR in LIF and LIF combined with rapamycin differentiation groups. (G and H) The relative mRNA expression of anti-inflammatory factors TGF- $\beta$ and IL-10, and pro-inflammatory factors TNF- $\alpha$ and IL-1 $\alpha$ on culture day 20 was detected by RT-qPCR in LIF and LIF combined with wortmannin differentiation groups. (I and J) The relative mRNA expression of anti-inflammatory factors TGF- $\beta$ and IL-10, and pro-inflammatory factors TNF- $\alpha$ and IL-1 $\alpha$ on culture day 20 was detected by RT-qPCR in LIF and LIF combined with rapamycin differentiation groups. Results are presented as the mean \pm standard deviation. " $\mathrm{P}<0.05$. AKT, protein kinase B; LY, LY294002; LIF, leukocyte inhibitory factor; MAP2, microtubule-associated protein 2; TUJ1, neuron-specific class III $\beta$-tubulin; TGF- $\beta$, transforming growth factor- $\beta$; IL, interleukin; RT-qPCR, reverse transcription-quantitative polymerase chain reaction; TNF- $\alpha$, tumor necrosis factor- $\alpha$; wortm, wortmannin; Rapa, rapamycin.

differentiation medium, and it was found to strongly improve the expression of the neuronal markers TUJ1 and MAP2, and the expression of p-AKT. p-AKT is a key composition of the PI3K/AKT signaling pathway; it serves an important role in neuronal proliferation and differentiation (18). Upregulating $\mathrm{p}$-AKT could increase the neuronal differentiation from mouse cochlear neural stem cells (19). In the present study, the
PI3K/AKT signal was inhibited by its inhibitor LY294002 and wortmannin in the LIF-positive differentiation group, and it was found that the protein expression of neuron markers TUJ1 and MAP2 was returned to a similar level in the two inhibitor groups as the control group. However, the same phenomenon was not found in the in the rapamycin-treated group, This may suggest that the greater neuronal differentiation effect in the 
LIF-positive differentiation group compared with that in the control differentiation group may occur through the activation of the PI3K/AKT signal, and that the mTOR signaling inhibition caused by LY294002 inhibitor or rapamycin may not participate in the greater neuronal differentiation and anti-inflammatory effect during the neuron differentiation from hiPSC-derived NPCs.

Anti-inflammation is one of the strategies to promote neuron protection and cell survival; it can reduce apoptosis and improve the survival of new derived neurons (25). The reaction of inflammation could regulate the expression of LIF. Injecting LPS into the trachea of a rat could induce the expression and secretion of LIF in bronchoalveolar cells (27). Meanwhile, inflammation-related cytokines such as IL- 6 and TNF- $\alpha$ could increase the mRNA or protein expression of LIF during the cell culture $(28,29)$. LIF upregulated the expression of anti-inflammatory cytokines, including IL-10 and TGF- $\beta$, and downregulated the expression of pro-inflammatory cytokines, including IL-1 $\alpha$ and TNF- $\alpha$, during the neuronal differentiation in the present study. Furthermore, LIF promoted the viability of the neurons during the differentiation. These data suggest the anti-inflammatory effect and cell survival effect of LIF on neuron differentiation. However, the expression of inflammatory cytokines and the cell viability were all reversed following the addition of PI3K/AKT inhibitor LY294002 and wortmannin to the LIF-positive differentiation group. Several studies revealed the involvement of PI3K/AKT signaling in metabolic dysfunction and inflammation. For example, furotrilliumoside prevented the LPS-induced upregulation of PI3K/AKT, as a result of which the expression of inflammatory cytokines TNF- $\alpha$, IL- 6 and IL-1 $\beta$ decreased (40). However, salvianolic acid A, a chemical type of caffeic acid trimer, blocks inflammatory responses through the activation of PI3K/AKT signaling (41). The present results suggested that the effect of LIF on inflammation and cell viability may be through the activation of PI3K/AKT signaling.

In conclusion, by use of a monolayer culture method, and N2/B27 basic medium combined with BMP inhibitor LDN193189 and TGF- $\beta$ inhibitor SB431542 during neural induction, a large proportion of derived NPCs was harvested. During the neuronal differentiation period from the derived NPCs, LIF can improve the differentiation by upregulating the protein expression of MAP2 and TUJ1, and increasing the number of TUJ1 and MAP2-positive neurons, which may be through the activation of PI3K/AKT signaling. In addition to this, LIF could exert the anti-inflammatory effect and improve the cell viability through activation of PI3K/AKT during neuronal differentiation. These data suggest that LIF serves an important role in the differentiation of neurons in vitro and may have a prospective application in the stem cell treatment of central nervous system diseases.

\section{Acknowledgements}

The authors appreciate the support of the Natural Science Foundation of Guangdong Province, China (grant no. 2016A030313584), the Characteristic Innovation Foundation of Innovative and Strong University Project of Guangdong Province, China (Education and Science Missive of Guangdong Province; grant no. 2014-65) and the Medical Research foundation of Guangdong Province,
China (grant no. B1432023). The authors would like to thank Professor Lan Feng for providing the hiPSCs and H9 cell lines.

\section{Competing interests}

The authors declare that they have no competing interests

\section{References}

1. Shiba Y, Gomibuchi T, Seto T, Wada Y, Ichimura H, Tanaka Y, Ogasawara T, Okada K, Shiba N, Sakamoto K, et al: Allogeneic transplantation of iPS cell-derived cardiomyocytes regenerates primate hearts. Nature 538: 388-391, 2016.

2. Hanna JH, Saha K and Jaenisch R: Pluripotency and cellular reprogramming: facts, hypotheses, unresolved issues. Cell 143: 508-525, 2010.

3. Wen Z, Nguyen HN, Guo Z, Lalli MA, Wang X, Su Y, Kim NS, Yoon KJ, Shin J,Zhang C, et al: Synaptic dysregulation in a human iPS cell model of mental disorders. Nature 515: 414-418, 2014.

4. Bakken TE, Miller JA, Ding SL, Sunkin SM, Smith KA, Ng L, Szafer A, Dalley RA, Royall JJ, Lemon T, et al: A comprehensive transcriptional map of primate brain development. Nature 535: 367-375, 2016.

5. Charrier JB, Lapointe F, Le Douarin NM and Teillet MA: Dual origin of the floor plate in the avian embryo. Development 129: 4785-4796, 2002.

6. Yan Y, Bejoy J, Xia J, Guan J,Zhou Y and Li Y: Neural patterning of human induced pluripotent stem cells in 3-D cultures for studying biomolecule-directed differential cellular responses. Acta Biomater 42: 114-126, 2016.

7. BrennandK,SavasJN,Kim Y,TranN,Simone A,Hashimoto-ToriiK, Beaumont KG, Kim HJ, Topol A, Ladran I, et al: Phenotypic differences in hiPSC NPCs derived from patients with schizophrenia. Mol Psychiatry 20: 361-368, 2015.

8. Davila J, Chanda S, Ang CE, Südhof TC and Wernig M: Acute reduction in oxygen tension enhances the induction of neurons from human fibroblasts. J Neurosci Methods 216: 104-109, 2013.

9. Liu F, Xuan A, Chen Y, Zhang J, Xu L, Yan Q and Long D: Combined effect of nerve growth factor and brain derived neurotrophic factor on neuronal differentiation of neural stem cells and the potential molecular mechanisms. Mol Med Rep 10: 1739-1745, 2014.

10. Metcalfe SM: LIF in the regulation of T-cell fate and as a potential therapeutic. Genes Immun 12: 157-168, 2011.

11. Yue $\mathrm{X}, \mathrm{Wu} \mathrm{L}$ and $\mathrm{Hu} \mathrm{W}$ : The regulation of leukemia inhibitory factor. Cancer Cell Microenviron 2: e877, 2015.

12. Burdon T, Smith A and Savatier P: Signalling, cell cycle and pluripotency in embryonic stem cells. Trends Cell Biol 12: 432-438, 2002.

13. Pera MF and Tam PP: Extrinsic regulation of pluripotent stem cells. Nature 465: 713-720, 2010.

14. Li X, Yang Q, Yu H, Wu L, Zhao Y, Zhang C, Yue X, Liu Z, Wu H, Haffty BG, et al: LIF promotes tumorigenesis and metastasis of breast cancer through the AKT-mTOR pathway. Oncotarget 5: 788-801, 2014.

15. Liu SC, Tsang NM, Chiang WC, Chang KP, Hsueh C, Liang Y, Juang JL, Chow KP and Chang YS: Leukemia inhibitory factor promotes nasopharyngeal carcinoma progression and radioresistance. J Clin Invest 123: 5269-5283, 2013.

16. Kanda M, Nagai T, Takahashi T, Liu ML, Kondou N, Naito AT, Akazawa H, Sashida G, Iwama A, Komuro I, et al: Leukemia inhibitory factor enhances endogenous cardiomyocyte regeneration after myocardial infarction. PLoS One 11: e0156562,2016.

17. Laszlo GS and Nathanson NM: Src family kinase-independent signal transduction and gene induction by leukemia inhibitory factor. J Biol Chem 278: 27750-27757, 2003.

18. Morell C, Bort A, Vara D, Ramos-Torres A, Rodríguez-Henche N and Díaz-Laviada I: The cannabinoid WIN 55,212-2 prevents neuroendocrine differentiation of LNCaP prostate cancer cells. Prostate Cancer Prostatic Dis 19: 248-257, 2016.

19. Zhang Y, He Q, Dong J, Jia Z, Hao F and Shan C: Effects of epigallocatechin-3-gallate on proliferation and differentiation of mouse cochlear neural stem cells: involvement of PI3K/Akt signaling pathway. Eur J Pharm Sci 88: 267-273, 2016.

20. Murphy M, Reid K, Hilton DJ and Bartlett PF: Generation of sensory neurons is stimulated by leukemia inhibitory factor. Proc Natl Acad Sci USA 88: 3498-3501, 1991. 
21. Li Y and Zang D: The neuron regrowth is associated with the proliferation of neural precursor cells after leukemia inhibitory factor administration following spinal cord injury in mice. PLoS One 9: e116031, 2014.

22. Lin C, Lin HY, Chen JH, Tseng WP, Ko PY, Liu YS, Yeh WL and Lu DY: Effects of paeonol on anti-neuroinflammatory responses in microglial cells. Int J Mol Sci 16: 8844-8860, 2015.

23. Fu SP, Wang JF, Xue WJ, Liu HM, Liu BR, Zeng YL, Li SN, Huang BX, Lv QK, Wang W, et al: Anti-inflammatory effects of BHBA in both in vivo and in vitro Parkinson's disease models are mediated by GPR109A-dependent mechanisms. J Neuroinflammation 12: 2015. doi: 10.1186/s12974-014-0230-3.

24. Jing Yh, Hou Yp, Song Yf and Yin J: Methylprednisolone improves the survival of new neurons following transient cerebral ischemia in rats. Acta Neurobiol Exp (Wars) 72: 240-252, 2012.

25. Tentillier N, Etzerodt A, Olesen MN, Rizalar FS, Jacobsen J, Bender D, Moestrup SK and Romero-Ramos M: Anti-inflammatory modulation of microglia via CD163-targeted glucocorticoids protects dopaminergic neurons in the 6-OHDA Parkinson's disease model. J Neurosci 36: 9375-9390, 2016.

26. Pal R, Tiwari PC, Nath R and Pant KK: Role of neuroinflammation and latent transcription factors in pathogenesis of Parkinson's disease. Neurol Res 38: 1111-1122, 2016.

27. Ulich TR, Fann MJ, Patterson PH, Williams JH, Samal B, Del Castillo J, Yin S, Guo K and Remick DG: Intratracheal injection of LPS and cytokines. V. LPS induces expression of LIF and LIF inhibits acute inflammation. Am J Physiol 267: L442-L446, 1994.

28. Knight DA, Lydell CP, Zhou D, Weir TD, Robert Schellenberg R and Bai TR: Leukemia inhibitory factor (LIF) and LIF receptor in human lung. Distribution and regulation of LIF release. Am J Respir Cell Mol Biol 20: 834-841, 1999.

29. Palmqvist $P$, Lundberg $P$, Lundgren I, Hänström $L$ and Lerner $U H$ IL-1beta and TNF-alpha regulate IL-6-type cytokines in gingival fibroblasts. J Dent Res 87: 558-563, 2008.

30. Kong Q, Zhang H, Zhao T, Zhang W, Yan M, Dong X and Li P Tangshen formula attenuates hepatic steatosis by inhibiting hepatic lipogenesis and augmenting fatty acid oxidation in $\mathrm{db} / \mathrm{db}$ mice. Int J Mol Med 38: 1715-1726, 2016.

31. Livak KJ and Schmittgen TD: Analysis of relative gene expression data using real-time quantitative PCR and the 2(- $\Delta \Delta C(T))$ method. Methods 25: 402-408, 2001.

32. Chen E, Xu D, Lan X, Jia B, Sun L, Zheng JC and Peng H: A novel role of the STAT3 pathway in brain inflammation-induced human neural progenitor cell differentiation. Curr Mol Med 13: $1474-1484,2013$.

33. Li YH, Fu HL, Tian ML, Wang YQ, Chen W, Cai LL, Zhou XH and Yuan HB: Neuron-derived FGF10 ameliorates cerebra ischemia injury via inhibiting NF- $\mathrm{NB}$-dependent neuroinflammation and activating PI3K/Akt survival signaling pathway in mice. Sci Rep 6: 19869, 2016.
34. Chau MJ, Deveau TC, Song M, Gu X, Chen D and Wei L: iPSC transplantation increases regeneration and functional recovery after ischemic stroke in neonatal rats. Stem Cells 32: 3075-3087, 2014

35. Chen C, Wang Y, Goh SS, Yang J, Lam DH, Choudhury Y, Tay FC, Du S, Tan WK, Purwanti YI, et al: Inhibition of neuronal nitric oxide synthase activity promotes migration of human-induced pluripotent stem cell-derived neural stem cells toward cancer cells. J Neurochem 126: 318-330, 2013.

36. Meneghini V, Frati G, Sala D, De Cicco S, Luciani M, Cavazzin C, Paulis M, Mentzen W, Morena F, Giannelli S, et al: Generation of human induced pluripotent stem cell-derived bona fide neural stem cells for ex vivo gene therapy of metachromatic leukodystrophy. Stem Cells Transl Med 6: 352-368, 2017

37. Chambers SM, Qi Y, Mica Y, Lee G, Zhang XJ, Niu L, Bilsland J, Cao L, Stevens E, Whiting P, et al: Combined small-molecule inhibition accelerates developmental timing and converts human pluripotent stem cells into nociceptors. Nat Biotechnol 30: 715-720, 2012.

38. Kirby ML, Kumiski DH, Myers T, Cerjan C and Mishima N: Backtransplantation of chick cardiac neural crest cells cultured in LIF rescues heart development. Dev Dyn 198: 296-311, 1993.

39. Laterza C, Merlini A, De Feo D, Ruffini F, Menon R, Onorati M, Fredrickx E, Muzio L, Lombardo A, Comi G, et al: iPSC-derived neural precursors exert a neuroprotective role in immune-mediated demyelination via the secretion of LIF. Nat Commun 4: 2597, 2013

40. Yan T, Yu X, Sun X, Meng D and Jia JM: A new steroidal saponin, furotrilliumoside from Trillium tschonoskii inhibits lipopolysaccharide-induced inflammation in Raw264.7 cells by targeting PI3K/Akt, MARK and Nrf2/HO-1 pathways. Fitoterapia 115: 37-45, 2016.

41. Chien MY, Chuang CH, Chern CM, Liou KT, Liu DZ, Hou YC and Shen YC: Salvianolic acid A alleviates ischemic brain injury through the inhibition of inflammation and apoptosis and the promotion of neurogenesis in mice. Free Radic Biol Med 99: 508-519, 2016.

This work is licensed under a Creative Commons Attribution-NonCommercial-NoDerivatives 4.0 International (CC BY-NC-ND 4.0) License. 